\title{
Oil-soluble ionic liquids as antiwear and extreme pressure additives in poly- $\alpha$-olefin for steel/steel contacts
}

\author{
Guowei HUANG ${ }^{1,2}$, Qiangliang YU ${ }^{1}$, Zhengfeng MA ${ }^{1}$, Meirong CAI ${ }^{1, *}$, Feng ZHOU $^{1, *}$, Weimin LIU $^{1}$ \\ ${ }^{1}$ State Key Laboratory of Solid Lubrication, Lanzhou Institute of Chemical Physics, Chinese Academy of Sciences, Lanzhou 730000, China \\ ${ }^{2}$ University of Chinese Academy of Sciences, Beijing 100049, China
}

Received: 01 April 2017 / Revised: 13 June 2017 / Accepted: 01 July 2017

(C) The author(s) 2017. This article is published with open access at Springerlink.com

\begin{abstract}
To enhance the lubricating and extreme pressure (EP) performance of base oils, two types of oil-soluble ionic liquids (ILs) with similar anion albeit dissimilar cations were synthesized. The physical properties of the prepared ILs were measured. The anticorrosion properties of ILs were assessed by conducting corrosion tests on steel discs and copper strips, which revealed the remarkable anticorrosion properties of the ILs in comparison with those of the commercial additive zinc dialkyldithiophosphate (ZDDP). The tribological properties of the two ILs as additives for poly- $\alpha$-olefin-10 (PAO10) with various mass concentrations were investigated. The tribological test results indicate that these ILs as additives are capable of reducing friction and wear of sliding contacts remarkably as well as enhance the EP performance of blank PAO10. Under similar test conditions, these IL additives exhibit higher lubricating and anti-wear (AW) performances than those of ZDDP based additive package in PAO10. Subsequently, X-ray photoelectron spectroscopy (XPS) and energy dispersive spectrometer (EDS) were conducted to study the lubricating mechanism of the two ILs. The results indicate that the formation of tribochemical film plays the most crucial role in enhancing the lubricating and AW behavior of the mixture lubricants.
\end{abstract}

Keywords: anti-wear; extreme pressure; ionic liquids; lubricating mechanism

\section{Introduction}

In practical operational conditions, friction and wear expend a large proportion of energy as well as damage instrument and apparatus [1,2]. Lubrication is the essential means to reduce friction and wear. The application of lubricants has been extensively employed as the main method to decrease friction and wear, which enables the mechanical equipment to operate efficiently. However, traditional lubricating oils have not exhibited the capability to satisfy the demands for higher mechanical efficiency and more complex service conditions. Therefore, a large number of additives, such as anti-wear (AW), extreme pressure (EP), dispersant, viscosity modifier, antioxidant, and anticorrosion have been synthesized to enhance the comprehensive performances of base oils and further lengthen the service life of operating components [3-5]. Meanwhile, the critical factors of lubricants, namely extreme pressure and lubricating performance, limit the application range of machineries and equipment in general [6]. Moreover, it is challenging to entirely satisfy the pragmatic requirements of new machinery and equipment, with traditional lubricating additives [7]. Therefore, it is necessary to research and synthesize new types of lubricant additives to satisfy the extreme conditions.

Recently, ILs have attracted considerable attention owing to their remarkable properties such as negligible volatility, high thermostability, low-melting-point, and regulated oil-solubility [7-10]. These remarkable characteristics make ILs employable as high-performance

* Corresponding authors: Meirong CAI, E-mail: caimr@licp.cas.cn; Feng ZHOU, E-mail: zhouf@licp.cas.cn 
lubricants or lubricant additives [11-15]. However, ILs exhibit inadequate solubility in conventional nonpolar hydrocarbon oil owing to their higher polarity. Accordingly, it is necessary to decrease the polarity of IL molecules when they are used as lubricant additives. Recently, a number of researchers have verified that an increase in the number of alkyl chains and enhancement of molecular symmetry can effectively reduce the polarity of ILs [16-19]. Hence, oil-solubility of ILs is enhanced significantly through the effective design of molecular structures [20]. Meanwhile, numerous studies have established that molecules containing sulfur and phosphorus exhibit adequate friction-reducing and AW performance, which is a consequence of the tribochemical reaction between the active elements (sulfur and phosphorus) and the fresh surface of the metal substrate [21-24]. Therefore, to further enhance the lubricating property of ILs, sulfur, and phosphorus can be introduced into the molecular structure by molecular design, and their percentage can be conveniently regulated in addition [14].

Based on the abovementioned concept, two types of quaternary ammonium and quaternary phosphonate ILs with similar anions are synthesized. Next, their tribological behavior as additives in PAO10 for steel/steel contacts is investigated at room temperature (RT). They exhibit more effective extreme pressure and lubricating properties than the traditional lubricant additive ZDDP (type: T204). Finally, the lubricating mechanism of the new ILs is studied through the chemical composition analysis of wear scars by XPS and EDS.

\section{Experimental details}

\subsection{Materials and synthesis}

Trioctylamine, trioctylphosphine, 1-bromohexadecane, and 2-chloroethyl ethyl sulfide were purchased from Energy Chemical. O, O-diethyl dithiophosphate ammonium salt was purchased from J\&K, and PAO10 as the base oil was bought from ExxonMobil. All the other chemical reagents used during the synthesis were of AR grade. The experiment was conducted according to the literature [25]. The product $\left[\left(\mathrm{C}_{8} \mathrm{H}_{17}\right)_{3} \mathrm{NC}_{16} \mathrm{H}_{33}\right]^{+}\left[\mathrm{C}_{4} \mathrm{H}_{10} \mathrm{O}_{2} \mathrm{PS}_{2}\right]^{-}\left(\mathrm{N}_{88816} \mathrm{~S}_{\mathrm{P}}\right)$ is a yellowish fluid, and $\left[\left(\mathrm{C}_{8} \mathrm{H}_{17}\right)_{3} \mathrm{PC}_{2} \mathrm{H}_{4} \mathrm{SC}_{2} \mathrm{H}_{5} \mathrm{C}_{16} \mathrm{H}_{33}\right]^{+}\left[\mathrm{C}_{4} \mathrm{H}_{10} \mathrm{O}_{2} \mathrm{PS}_{2}\right]^{-}$
$\left(\mathrm{P}_{8885} \mathrm{~S}_{\mathrm{P}}\right)$ is a colorless and thick fluid. The molecular structures of the two ILs are depicted in Fig. 1. The cations of the two types of ILs exhibiting threedimensional quaternary structures can pair with dithiophosphate containing long hydrocarbon chains, and both the ions can generate high steric hindrance so as to screen the charge of the ions. Therefore, the polarity of ILs are significantly reduced. Consequently, the two types of ILs exhibit higher oil solubility than traditional imidazolium-based ILs such as 1-hexyl-3methylimidazolium tetrafluoroborate (LB106) and 1-butyl-3-methylimidazolium bis[(trifluoromethyl)sulfonyl]imide (LF104). Then, the two ILs were added in PAO10 at various mass concentrations $(0.5 \%, 1.0 \%$, $1.5 \%$, and $2.0 \%$ ) and stirred until the mixtures became uniform and transparent.

\subsection{Characterization}

The lubricating performance of blank PAO10 and the mixtures was tested by the ball-on-disc testing machine Optimol SRV-IV oscillating reciprocating friction and wear tester. Prior to the tests, the steel discs were wet polished with emery papers of grades $400,800,1,200$, and 1,500 successively and finally polished with cloth using a metallographic sample polishing machine. The mixture was dropped into the ball-disk contact area. The friction coefficients were automatically recorded by the computer linked to the SRV machine. After completion of the tests, the surfaces of the discs are wiped several times with absorbent cotton balls saturated in petroleum ether to thoroughly remove the lubricants on the surfaces of discs in preparation for conducting the subsequent test. Three repetitive measurements were carried out for each friction test. After all the tests were completed, the steel discs are cleaned several times ultrasonically in baths of petroleum ether. Then, the treated discs are removed and dried at room temperature for subsequent utilization.

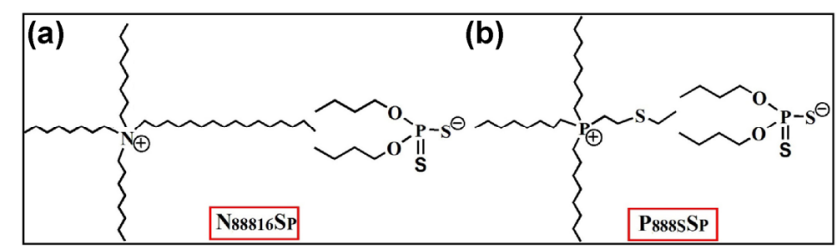

Fig. 1 Experimental set-up. 
The diameter of the steel ball (type: AISI 52100) is $10 \mathrm{~mm}$. The hardness of the stationary steel disk (type: AISI 52100) is approximately 66-68 HRC. The roughness of the steel ball and disc are approximately $0.02 \mu \mathrm{m}$ and $0.2 \mu \mathrm{m}$, respectively. All the tribological tests are conducted at room temperature. When the loads are $300 \mathrm{~N}$ and $500 \mathrm{~N}$, the maximum Hertzian pressures are approximately $3.039 \mathrm{GPa}$ and $3.603 \mathrm{GPa}$, respectively. Sliding speeds $(v)$ are determined by amplitude $(A)$ and frequency $(f)$. Here, $A$ is a constant $\left(1.0 \times 10^{-3} \mathrm{~m}\right)$, and $f$ is a specified value. Sliding speeds of friction components at various frequencies are provided in Table 1. MicroXAM 3D noncontact surface mapping profiler was adopted to measure the wear volumes of the lower discs. Scanning electron microscope (SEM) (type: JSM-5600LV), XPS (type: PHI-5702), and EDS were employed to analyze the surface morphologies and chemical composition of wear scars, respectively. The four-ball tester (type: MRS-10A) was used to investigate the maximum non-seizure loads (PB).

Time-of-flight mass spectrometry (TOFMS, type: Bruker micrOTOF Q II) was adopted to investigate the molecular weights of cations and anions of $\mathrm{N}_{88816} \mathrm{~S}_{\mathrm{P}}$ and $\mathrm{P}_{8885} \mathrm{~S}_{\mathrm{P}}$, as illustrated in Fig. 2. Thereinto, Figs. 2(a) and 2(c) depict the molecular weights of cations of $\mathrm{N}_{88816} \mathrm{~S}_{\mathrm{P}}$ (579.6593) and $\mathrm{P}_{8885} \mathrm{~S}_{\mathrm{P}}$ (459.4118), respectively, and they are in accordance with the calculated values (579.10 and 459.42, respectively). Figures 2(b) and 2(d) correspond to the anions of [SP] ${ }^{-}$(241.0631 and 241.0645), which are also consistent with the calculated value (241.05). Meanwhile, no apparent impurity peaks are observed in the mass spectrometry results. The aforementioned results indicate that the molecular structures of $\mathrm{N}_{88816} \mathrm{~S}_{\mathrm{P}}$ and $\mathrm{P}_{8885} \mathrm{~S}_{\mathrm{P}}$ are correct and that their purities are substantially high.

Ubbelohde viscometer was adopted to measure the kinematic viscosities of ZDDP, $\mathrm{N}_{88816} \mathrm{~S}_{\mathrm{P}}$, and $\mathrm{P}_{8885} \mathrm{~S}_{\mathrm{P}}$ at 25,40 , and $100{ }^{\circ} \mathrm{C}$, as illustrated in Table 2 . It is observed that the viscosity indexes of $\mathrm{N}_{88816} \mathrm{~S}_{\mathrm{P}}$ and $\mathrm{P}_{8885} \mathrm{~S}_{\mathrm{P}}$ are approximately 144 and 128, respectively, which are higher than that of ZDDP (104). The above results

Table 1 Sliding speeds of friction pairs at various frequencies.

\begin{tabular}{ccccccc}
\hline Frequency $(\mathrm{Hz})$ & 15 & 20 & 25 & 30 & 35 & 40 \\
\hline $\begin{array}{c}\text { sliding speed } \\
\left(10^{-2} \mathrm{~m} / \mathrm{s}\right)\end{array}$ & 3.0 & 4.0 & 5.0 & 6.0 & 7.0 & 8.0 \\
\hline
\end{tabular}
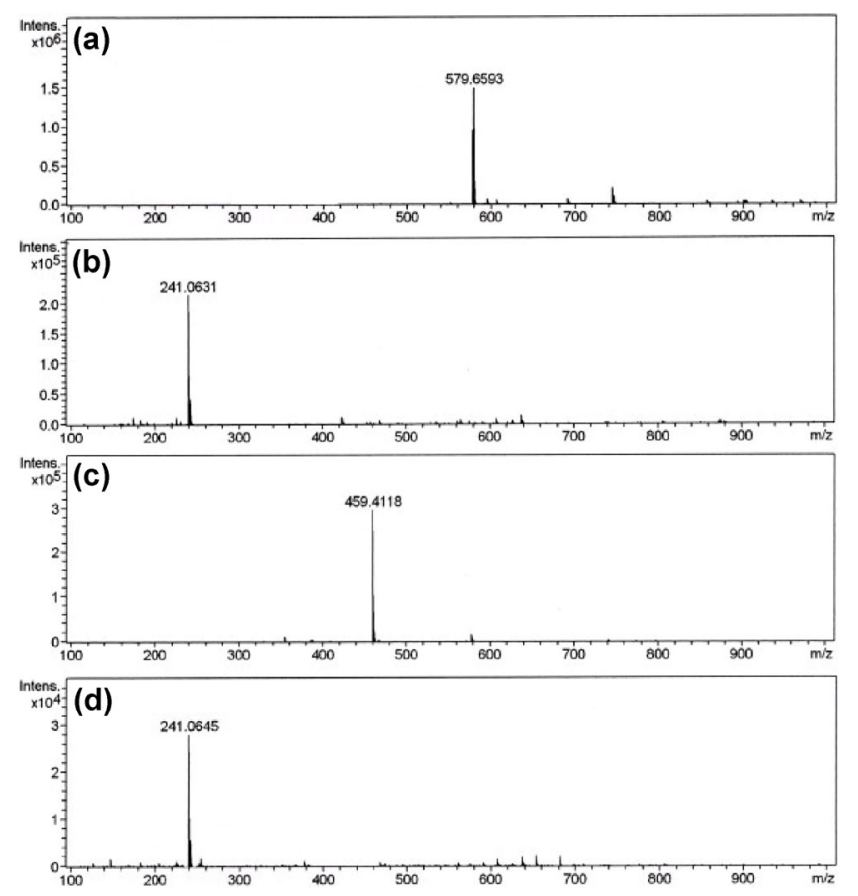

Fig. 2 Time-of-flight mass spectrometry of $\mathrm{N}_{88816} \mathrm{~S}_{\mathrm{P}}$ and $\mathrm{P}_{888 \mathrm{~S}} \mathrm{~S}_{\mathrm{P}}$ : (a, c) describe the cations $\left[\mathrm{N}_{88816}\right]^{+}$and $\left[\mathrm{P}_{888 \mathrm{~S}}\right]^{+}$and $(\mathrm{b}, \mathrm{d})$ describe the anions of $[\mathrm{SP}]^{-}$.

Table 2 Kinematic viscosities $\left(\mathrm{mm}^{2} / \mathrm{s}\right)$ of ZDDP, $\mathrm{N}_{88816} \mathrm{~S}_{\mathrm{P}}$, and $\mathrm{P}_{888 \mathrm{~S}} \mathrm{~S}_{\mathrm{P}}$ at 25,40 , and $100{ }^{\circ} \mathrm{C}$

\begin{tabular}{|c|c|c|c|c|}
\hline \multirow{2}{*}{ Lubricant } & \multicolumn{3}{|c|}{ Kinematic viscosities $\left(\mathrm{mm}^{2} / \mathrm{s}\right)$} & \multirow{2}{*}{$\begin{array}{c}\text { Viscosity } \\
\text { index }\end{array}$} \\
\hline & $25^{\circ} \mathrm{C}$ & $40{ }^{\circ} \mathrm{C}$ & $100{ }^{\circ} \mathrm{C}$ & \\
\hline ZDDP & 503.3 & 207.8 & 19.2 & 104 \\
\hline $\mathrm{N}_{88816} \mathrm{~S}_{\mathrm{P}}$ & 267.3 & 121.7 & 16.3 & 144 \\
\hline $\mathrm{P}_{888 \mathrm{~S}} \mathrm{~S}_{\mathrm{P}}$ & $1,050.8$ & 418.3 & 36.1 & 128 \\
\hline
\end{tabular}

indicate that temperature exerts lesser influence on the viscosities of the two ILs than it does on that of ZDDP [26]. Therefore, the two ILs are suitable for use in more stringent conditions such as varying temperature and high temperature.

\subsection{Corrosion and electrochemical measurements}

Before the corrosion tests, the surfaces of the copper pieces (dimensions: $10 \mathrm{~mm} \times 10 \mathrm{~mm} \times 3 \mathrm{~mm}$ ) and steel discs (AISI 52100, dimensions: $10 \mathrm{~mm} \times 10 \mathrm{~mm} \times$ $3 \mathrm{~mm}$ ) were polished with emery papers (grades 400-600-800-1200-1500). The treated samples were successively cleaned by ultrapure water and ethanol. Then, the samples were dried and placed in the weighing bottles $(2.5 \mathrm{~cm} \times 2.5 \mathrm{~cm})$. The corresponding lubricants $(8 \mathrm{~g})$ were added into the labeled bottles. 
The weighing bottles containing the samples and corresponding lubricants were placed in an incubator at $120{ }^{\circ} \mathrm{C}$ for $5 \mathrm{~h}$. Finally, the treated copper pieces and steel discs were withdrawn from the bottles and rinsed thoroughly with copious ethanol to remove the lubricants.

Electrochemical tests were conducted by threeelectrode system (type: VoltaLab 40) at RT, thereinto, the saturated calomel electrode and platinum electrode were used as the reference electrode and counter electrode, respectively. The rod of steel (type: Q235) functioning as the electrode (the area of the working surface $=0.7 \mathrm{~cm}^{2}$ ) was embedded in PVC pipeline with epoxy resin. The operating surface was polished with emery papers (grades 400-800-1200-1500). Then, the treated surface was cleaned by ultrasound in water and in acetone successively. Before the tests, the electrodes were immersed in ethanol at OCP (open circuit potential) until a steady state was achieved.

\section{Results and discussion}

\subsection{Tribological tests and surface analysis}

Friction coefficient (COF) and wear volume can intuitively reflect the friction-reducing and AW performance of lubricants [27-29]. Therefore, the tribological properties of neat PAO10 and the mixtures with various mass concentrations of $\mathrm{N}_{88816} \mathrm{~S}_{\mathrm{P}}$ and $\mathrm{P}_{8885} \mathrm{~S}_{\mathrm{P}}$ are investigated at $300 \mathrm{~N}, 25 \mathrm{~Hz}$, and $\mathrm{RT}$, as described in Fig. 3. The COF of PAO10 increases up to approximately 0.63 at approximately $160 \mathrm{~s}$ and then rapidly reduces to approximately 0.25 , indicating that PAO10 exhibits inadequate lubricating performance when the load is $300 \mathrm{~N}$. The mixtures exhibit higher performance and more stable lubricating behavior compared with the neat PAO10, and the values of COFs are approximately 0.12 and 0.11 when $\mathrm{N}_{88816} \mathrm{SP}$ and $\mathrm{P}_{8885} \mathrm{~S}_{\mathrm{P}}$, respectively, are used as the additive, as depicted in Figs. 3(a) and 3(b). Meanwhile, it is also observed that the mixtures exhibit adequate lubricating performance notwithstanding low mass concentration $(0.5 \%)$, indicating that the two ILs as lubricant additives exhibit high-efficiency and reliability. The corresponding wear volumes are also measured to characterize the AW properties of neat PAO10 and the mixtures, as described in Figs. 3(c) and 3(d). The wear volume of the wear scar lubricated by PAO10 is approximately $23 \times 10^{5} \mu^{3}$, and it is remarkably decreased to approximately $1.7 \times 10^{5} \mu \mathrm{m}^{3}$ when employing the mixtures as lubricants. The above results verify that the two ILs as lubricant additives exhibit adequate frictionreducing and $\mathrm{AW}$ properties, revealing that they are suitable for employment as candidates for AW lubricant additives.

SEM as a powerful technique has been extensively employed to investigate the surface morphologies of wear scars and further identify the wear types [30]. Figure 4 depicts the SEM images of worn surfaces of steel discs lubricated by neat PAO10 and mixtures
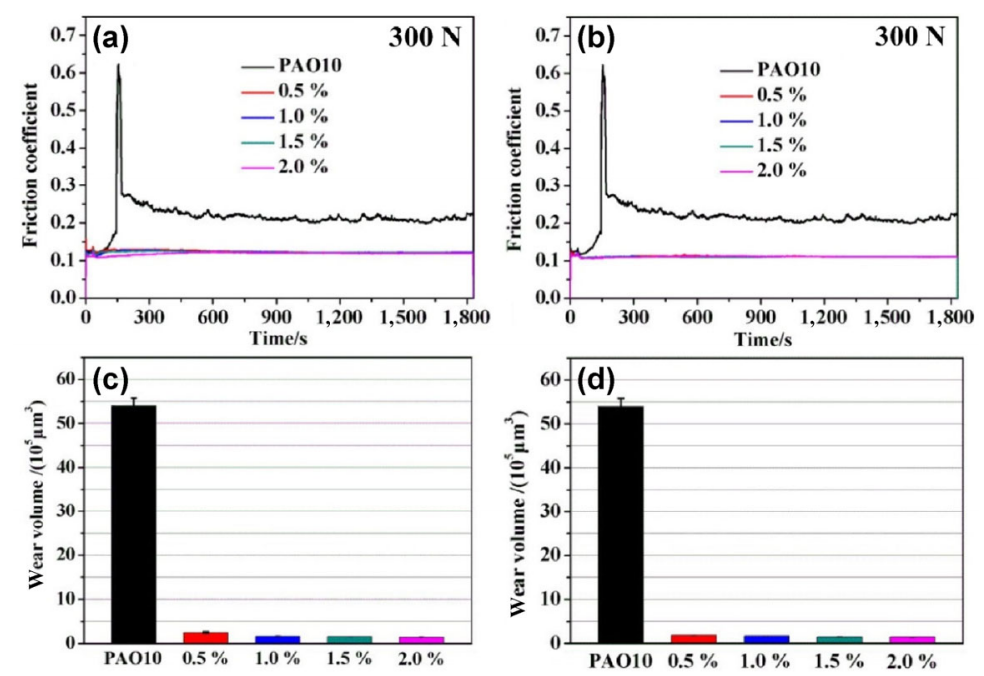

Fig. 3 Friction-reducing and anti-wear properties of (a, c) $\mathrm{N}_{88816} \mathrm{~S}_{\mathrm{P}}$ and (b, d) $\mathrm{P}_{888 \mathrm{~S}} \mathrm{~S}_{\mathrm{P}}$ at different mass concentration for steel/steel contacts at $300 \mathrm{~N}, 25 \mathrm{~Hz}$, and RT. 


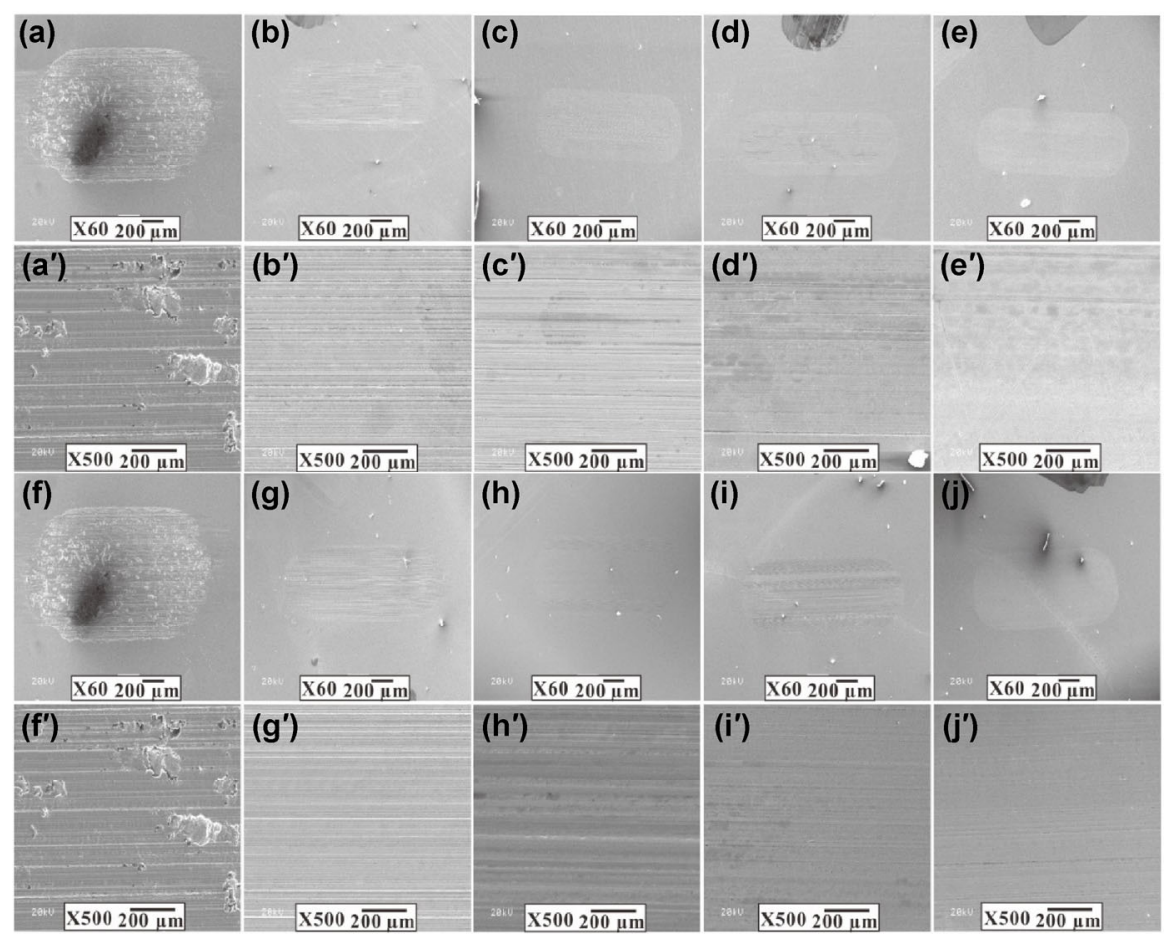

Fig. 4 SEM images of worn surfaces of steel disks lubricated by $\left(\mathrm{a}, \mathrm{a}^{\prime}, \mathrm{f}, \mathrm{f}^{\prime}\right)$ neat PAO10; mixtures with various mass concentrations of (b-e, b'-e') $\mathrm{N}_{88816} \mathrm{~S}_{\mathrm{P}}$ and $\left(\mathrm{g}-\mathrm{j}, \mathrm{g}^{\prime}-\mathrm{j}^{\prime}\right) \mathrm{P}_{888 \mathrm{~S}} \mathrm{~S}_{\mathrm{P}}$ : (b, b', g, g') $0.5 \mathrm{wt} \%,\left(\mathrm{c}, \mathrm{c}^{\prime}, \mathrm{h}, \mathrm{h}^{\prime}\right) 1.0 \mathrm{wt} \%,\left(\mathrm{~d}, \mathrm{~d}^{\prime}, \mathrm{i}, \mathrm{i}^{\prime}\right) 1.5 \mathrm{wt} \%,\left(\mathrm{e}, \mathrm{e}^{\prime}, \mathrm{j}, \mathrm{j}^{\prime}\right) 2.0 \mathrm{wt} \%, \mathrm{test}$ conditions: $300 \mathrm{~N}, 25 \mathrm{~Hz}$ and RT.

with various mass concentrations of $\mathrm{N}_{88816} \mathrm{~S}_{\mathrm{P}}$ and $\mathrm{P}_{8885} \mathrm{~S}_{\mathrm{P}}$. It is apparent that the diameters of wear scars are significantly decreased when the mixtures are adopted as the lubricants. Meanwhile, the alteration of the wear scar diameters is marginal with the increase of mass concentrations of the ILs, which is in accordance with their lubricating performance, as illustrated in Fig. 3. Moreover, the wear types are correspondingly altered as illustrated in Figs. $4\left(\mathrm{a}^{\prime}\right)-4\left(\mathrm{e}^{\prime}\right)$ and Figs. $4\left(\mathrm{f}^{\prime}\right)$ $4\left(j^{\prime}\right)$. The dominant wear forms are abrasion and fatigue wear when employing neat PAO10 as the lubricant, as depicted in Figs. $4\left(\mathrm{a}^{\prime}\right)$ and $4\left(\mathrm{f}^{\prime}\right)$. Furthermore, for the mixtures, the light abrasion wear becomes the major wear type, as depicted in Figs. $4\left(b^{\prime}\right)-4\left(e^{\prime}\right)$ and Figs. $4\left(g^{\prime}\right)-4\left(j^{\prime}\right)$.

\subsection{Control tests}

\subsubsection{Normal and frequency ramp tests}

Control tests were conducted to further assess the lubricating properties of the two ILs compared with the generally used lubricant additives. ZDDP as an organic metal type additive has been extensively applied in engine oils for more than 70 years owing to their remarkable antioxidation and lubricating property [31,32]. Meanwhile, the mixtures have exhibited adequate lubricating performance at low mass concentrations; hence, the concentration of $1.0 \mathrm{wt} \%$ was selected during the control tests. The corresponding results are illustrated in Fig. 5. The mixtures containing similar mass concentrations of ZDDP and $\mathrm{N}_{88816} \mathrm{~S}_{\mathrm{P}}$ exhibit similar antifriction performance, and the value of COFs are approximately 0.12 . Moreover, the mixture with $\mathrm{P}_{8885} \mathrm{~S}_{\mathrm{P}}$ as the additive exhibits the highest friction-reducing property, and the corresponding value of COF is approximately 0.11 . The factor behind this is discussed in the following section. The mixtures with $\mathrm{N}_{88816} \mathrm{~S}_{\mathrm{P}}$ and $\mathrm{P}_{8885} \mathrm{~S}_{\mathrm{P}}$ as the additives also exhibit smaller wear volumes (approximately $1.75 \times 10^{5} \mu \mathrm{m}^{3}$ and $1.6 \times 10^{5} \mu \mathrm{m}^{3}$, respectively) than the one containing $1 \mathrm{wt} \%$ ZDDP (approximately $\left.2.4 \times 10^{5} \mu \mathrm{m}^{3}\right)$. The aforementioned results indicate that the two ILs exhibit friction reduction property comparable to that of the traditional lubricant additive ZDDP; however, they exhibit higher AW performance at $300 \mathrm{~N}$. 

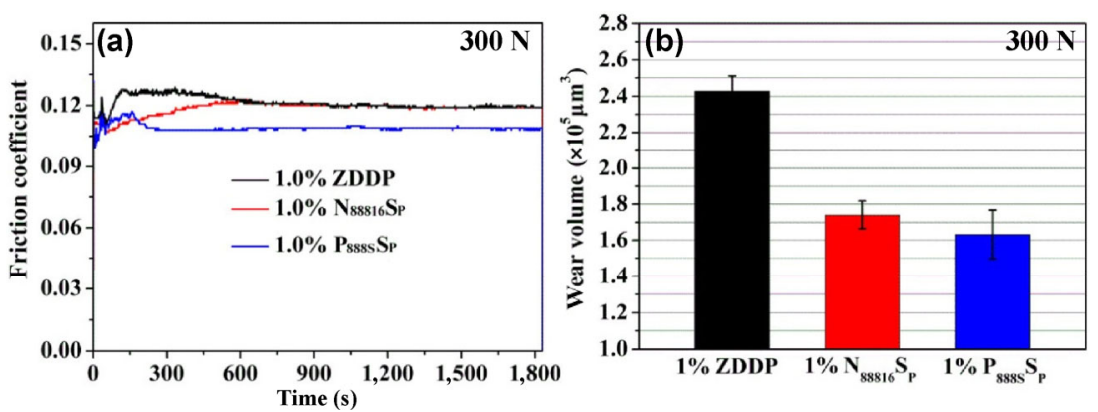

Fig. 5 Friction-reducing and anti-wear properties of ZDDP, $\mathrm{N}_{88816} \mathrm{~S}_{\mathrm{P}}$, and $\mathrm{P}_{888 \mathrm{~S}} \mathrm{~S}_{\mathrm{P}}$ at similar mass concentrations of $1.0 \%$ for steel/steel contacts at $300 \mathrm{~N}, 25 \mathrm{~Hz}$, and RT.

The challenging conditions limit the application range of lubricants and also reflect their qualities [6]. Therefore, the frequency ramp tests were conducted to evaluate the lubricating performance of the two ILs in comparison with ZDDP under harsh conditions, as illustrated in Fig. 6. It is evident that the COF of the mixture containing $1 \mathrm{wt} \%$ ZDDP increases with increase in frequency, and the maximum value of $\mathrm{COF}$ is approximately 0.13 , as illustrated in Fig. 6(a). The corresponding AW performance becomes inadequate, and the wear volume is approximately $10.2 \times 10^{5} \mu \mathrm{m}^{3}$, which arises from the increase in friction and the deterioration of lubricating property. Meanwhile, for the mixtures containing ILs at similar mass concentration, the values of COFs decrease as time elapses, and the final values are approximately 0.10 . Furthermore, the corresponding wear volumes are approximately $5.5 \times 10^{5} \mu^{3}$ and $4.9 \times 10^{5} \mu^{3}$ when $\mathrm{N}_{88816} \mathrm{~S}_{\mathrm{P}}$ and $\mathrm{P}_{8885} \mathrm{~S}_{\mathrm{P}}$, respectively, are adopted as the additives, which represents marginal variations from the ones at $25 \mathrm{~Hz}$, as illustrated in Fig. 3. The above results verify that the two types of ILs as lubricant additives exhibit higher lubricating and AW perfor- mances than ZDDP under harsh conditions at similar mass concentration.

\subsubsection{Extreme-pressure performance tests}

To investigate the EP properties of the two ILs as lubricant additives, the maximum non-seizure load (PB) were measured by a four ball machine. The experiment was conducted according to the national standard GB/T3142-82, and the steel ball (GGr15) with a diameter of $12.7 \mathrm{~mm}$ exhibits hardness of 61-65 HRC [33]. The corresponding experimental results are illustrated in Fig. 7. It is observed that the PB value of the mixture with $1 \mathrm{wt} \%$ ZDDP is $94 \mathrm{~kg}$, establishing the adequate EP performance of ZDDP. Moreover, EP property is remarkably enhanced when the ILs are used as the additives, and the corresponding values are $181 \mathrm{~kg}$ and $121 \mathrm{~kg}$ for the mixtures containing $\mathrm{N}_{88816} \mathrm{~S}_{\mathrm{P}}$ and $\mathrm{P}_{8885} \mathrm{~S}_{\mathrm{P}}$, respectively. The above results demonstrate that the two ILs as lubricant additives exhibit higher EP property than that of ZDDP at similar mass concentration. Meanwhile, PB as a critical performance parameter of lubricants can reflect the compressive strength of the adsorption film formed
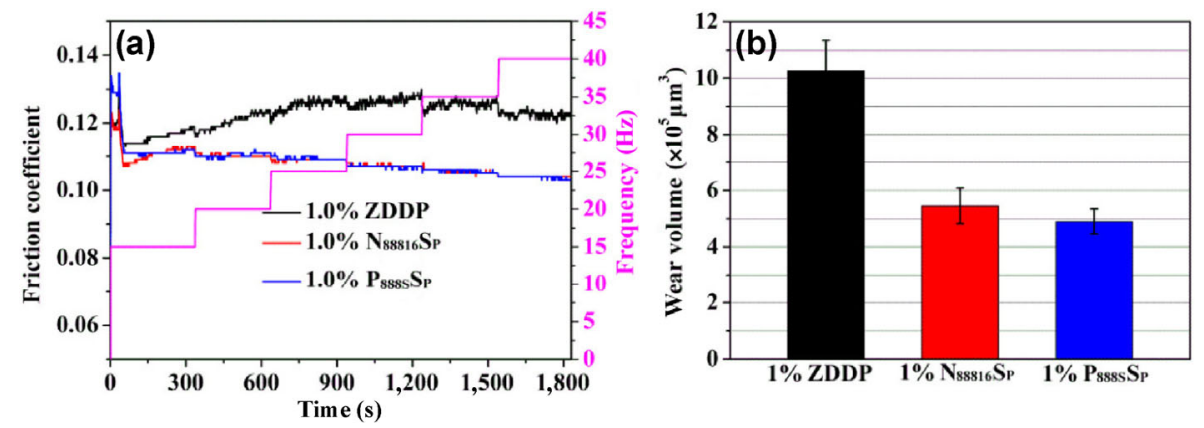

Fig. 6 Friction-reducing and anti-wear properties of ZDDP, $\mathrm{N}_{88816} \mathrm{~S}_{\mathrm{P}}$, and $\mathrm{P}_{888 \mathrm{~S}} \mathrm{~S}_{\mathrm{P}}$ at mass concentration of $1.0 \%$ for steel/steel contacts at $300 \mathrm{~N}$ and $25 \mathrm{~Hz}$ when the frequency varies from $15 \mathrm{~Hz}$ to $40 \mathrm{~Hz}$. 


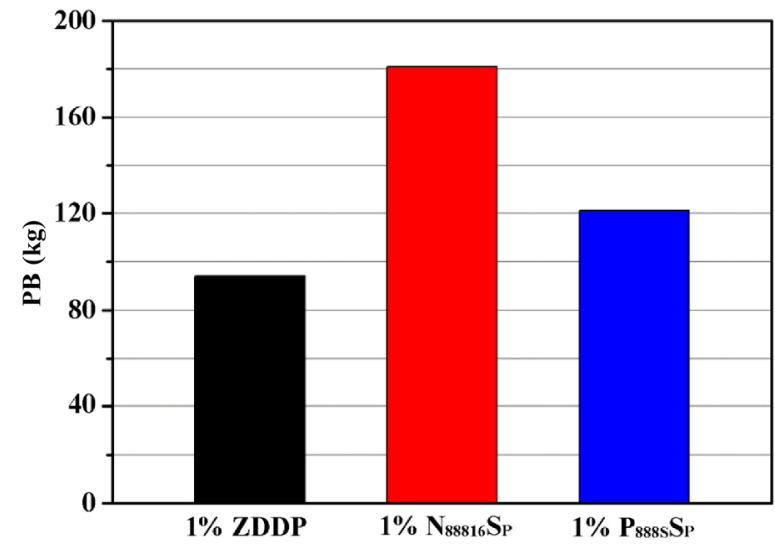

Fig. 7 Maximum non-seizure loads of ZDDP, N88816SP, and P888SSP at mass concentration of $1.0 \%$.

by the lubricant on the metal surface [34]. Therefore, the aforementioned results also establish that the two ILs exhibit higher adsorption performance on the steel surface than that exhibited by ZDDP.

\subsection{Corrosion and electrochemical tests}

In the process of friction, the lubricants are likely to be contaminated and oxidized to certain extent, which results in corrosion and wear of the rubbing surfaces [4,35]. ZDDP as corrosion inhibitor and antioxidant has aroused scholars' extensive interest and been widely studied; it is the generally-used lubricant additive [36]. Therefore, it is necessary to study the corrosion property of the two ILs when they are employed as lubricant additives. The accelerated corrosion tests were carried out to compare the anticorrosion properties between the two ILs and ZDDP. The pure copper pieces (dimensions: $10 \mathrm{~mm} \times 10 \mathrm{~mm} \times$ $3 \mathrm{~mm}$ ) and steel discs (type: AISI 52100, dimensions: $10 \mathrm{~mm} \times 10 \mathrm{~mm} \times 3 \mathrm{~mm}$ ) were incubated in neat PAO10, ILs, and ZDDP at $120^{\circ} \mathrm{C}$ for $5 \mathrm{~h}$. The test results are presented in Fig. 8. It is observed that the colors of the steel disc and copper piece treated by neat PAO10 exhibit negligible variation indicating that PAO10 has little corrosion to the metal surfaces. Moreover, the colors of the surfaces of the steel discs and copper pieces become dark after being treated with ZDDP, particularly the copper pieces, indicating that ZDDP exhibits low corrosion resistance property at high temperature. Meanwhile, for the steel discs and copper pieces treated by the two ILs, the colors vary marginally, implying that corrosion is significantly reduced. The above results reveal that the two ILs exhibit higher corrosion resistance properties than that of ZDDP. Meanwhile, the reasonable corrosion resistance property can partly reduce the wear in the process of friction [37].

The polarization curves of Q235 carbon steel in ethanol using $1 \mathrm{wt} \%$ ZDDP, $1 \mathrm{wt} \% \mathrm{~N}_{88816} \mathrm{~S}_{\mathrm{P}}$, and $1 \mathrm{wt} \% \mathrm{P}_{8885} \mathrm{~S}_{\mathrm{P}}$ as corrosion inhibitors were obtained to further investigate their corrosion performance, as illustrated in Fig. 9. All the electrochemical tests were conducted after the immersion of the three electrodes in ethanol for approximately $30 \mathrm{~min}$ at the OCP. The potentiodynamic tests were carried out in the potential range from $-250 \mathrm{mV}$ to $+250 \mathrm{mV}$ vs. the $\mathrm{OCP}$, and the scan rate is $10 \mathrm{mV} / \mathrm{min}$. Electrochemical impedance spectroscopy (EIS) was conducted at the OCP, and the frequency was in the range from $100 \mathrm{kHz}$ to $10 \mathrm{mHz}$ with an amplitude signal of $5 \mathrm{mV}$. When $1 \mathrm{wt} \%$ ZDDP (OCP: $-0.126 \mathrm{~V}), \mathrm{N}_{88816} \mathrm{~S}_{\mathrm{P}}(\mathrm{OCP}:-0.113 \mathrm{~V})$, and $1 \mathrm{wt} \%$ $\mathrm{P}_{8885} \mathrm{~S}_{\mathrm{P}}$ (OCP: $-0.104 \mathrm{~V}$ ) are used as the corrosion inhibitors, the corrosion potentials are approximately $-0.129 \mathrm{~V},-0.044 \mathrm{~V}$, and -0.068 , respectively. Moreover, the corresponding corrosion currents are obtained through the linear extrapolation, and they are approximately $1.06 \times 10^{-7} \mathrm{~A}, 4.51 \times 10^{-8} \mathrm{~A}$, and $5.36 \times 10^{-8} \mathrm{~A}$, respectively. The above results intuitively indicate that the two types of ILs exhibit higher corrosion resistance than that of ZDDP.

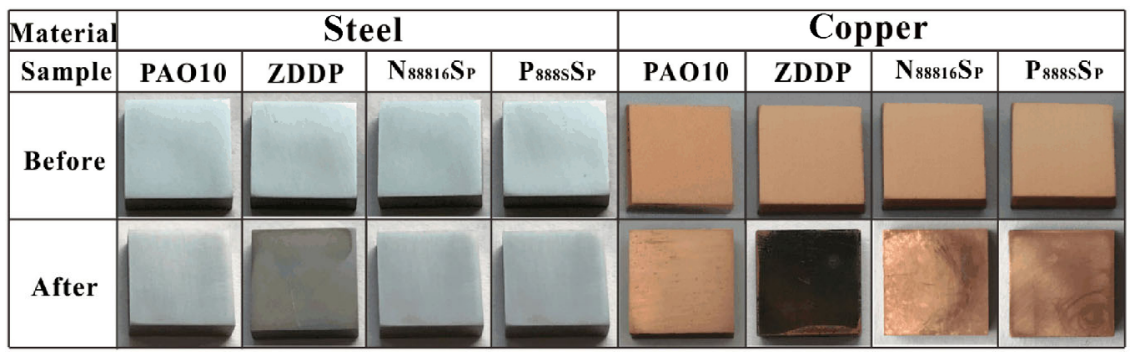

Fig. 8 Photographs of steel discs and copper pieces before and after corrosion tests at $120{ }^{\circ} \mathrm{C}$ for $5 \mathrm{~h}$. 


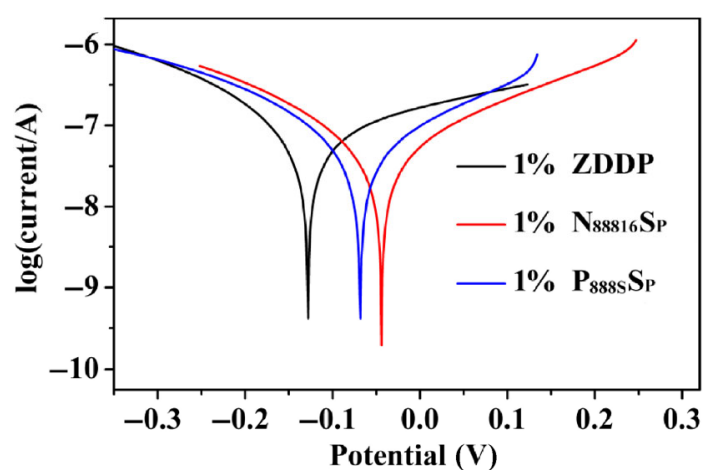

Fig. 9 Polarization curves of Q235 carbon steel in ethanol using $1 \mathrm{wt} \% \mathrm{ZDDP}, 1 \mathrm{wt} \% \mathrm{~N}_{88816} \mathrm{~S}_{\mathrm{P}}$, and $1 \mathrm{wt} \% \mathrm{P}_{888 \mathrm{~S}} \mathrm{~S}_{\mathrm{P}}$ as the corrosion inhibitors.

\subsection{Compatibility with ZDDP}

ZDDP as an effective lubricant additive can cause ash deposits as a result of its thermal decomposition, and the zinc in the molecules plays the dominant role in poisoning the emission purification catalysts and polluting the environment [38]. Accordingly, it is necessary to develop high efficiency and alternative additives to reduce the dosage of ZDDP. First, load ramp-up tests were conducted when the mass concentration of ILs and ZDDP is 1\%. The "ramp-up" tests here signify that the tests were conducted at $300 \mathrm{~N}$ and $500 \mathrm{~N}$, and they were discontinuous. The test conditions are $300 \mathrm{~N}, 25 \mathrm{~Hz}$, and RT and $500 \mathrm{~N}, 25 \mathrm{~Hz}$, and RT, respectively. When the load shifts from $300 \mathrm{~N}$ to $500 \mathrm{~N}$, the COF of the mixture with $1 \mathrm{wt} \%$ ZDDP increases remarkably, and the value is approximately 0.5 at 100 s, as illustrated in Fig. 10(a). Moreover, lasting for approximately $150 \mathrm{~s}$, the value of COF reduces to approximately 0.15 . Meanwhile, the corresponding wear volume is obtained and is approximately $80 \times 10^{5} \mu \mathrm{m}^{3}$.
Meanwhile, for the mixtures containing the ILs, the COFs are approximately 0.11 , and they are highly smooth and stable in the whole process of friction; furthermore, the wear volumes are approximately $5.0 \times 10^{5} \mu \mathrm{m}^{3}$ as illustrated in Fig. 10(b). The aforementioned results indicate that the two ILs as the additives of PAO10 exhibit higher load-carrying capacity than that of ZDDP when the load shifts from $300 \mathrm{~N}$ to $500 \mathrm{~N}$.

Then, $\mathrm{N}_{88816} \mathrm{~S}_{\mathrm{P}}$ and $\mathrm{P}_{8885} \mathrm{~S}_{\mathrm{P}}$ are added to ZDDP to decrease its dose and further enhance its EP and lubricating performance. To reduce the relative amount of ZDDP, the mass concentrations of ILs is not to be maintained at negligible values. Therefore, the mass concentration of $0.5 \%$ was selected. No seizure is observed at $500 \mathrm{~N}$ when the two ILs are mixed with ZDDP in 1:1 mass ratio, as illustrated in Fig. 10(a). Meanwhile, the COFs decrease from 0.15 to 0.12 , and the corresponding wear volumes are reduced from $80 \times 10^{5} \mu \mathrm{m}^{3}$ to approximately $20 \times 10^{5} \mu \mathrm{m}^{3}$, as depicted in Fig. 10(b). The above results indicate that $\mathrm{N}_{88816} \mathrm{~S}_{\mathrm{P}}$ and $\mathrm{P}_{8885} \mathrm{~S}_{\mathrm{P}}$ can remarkably enhance the EP and lubricating behavior of ZDDP. Moreover, it has been established that this phenomenon can be attributed to the synergistic effects between ILs and ZDDP [39]. Therefore, it is feasible for the two ILs to partly or completely replace ZDDP for practical use, and this is highly likely to decrease the toxicity caused by zinc to the catalyst system.

\subsection{Study of the lubricating mechanism}

\subsubsection{XPS spectra of wear scar surfaces}

XPS as an effective tool has been extensively utilized to study element distribution and chemical states of
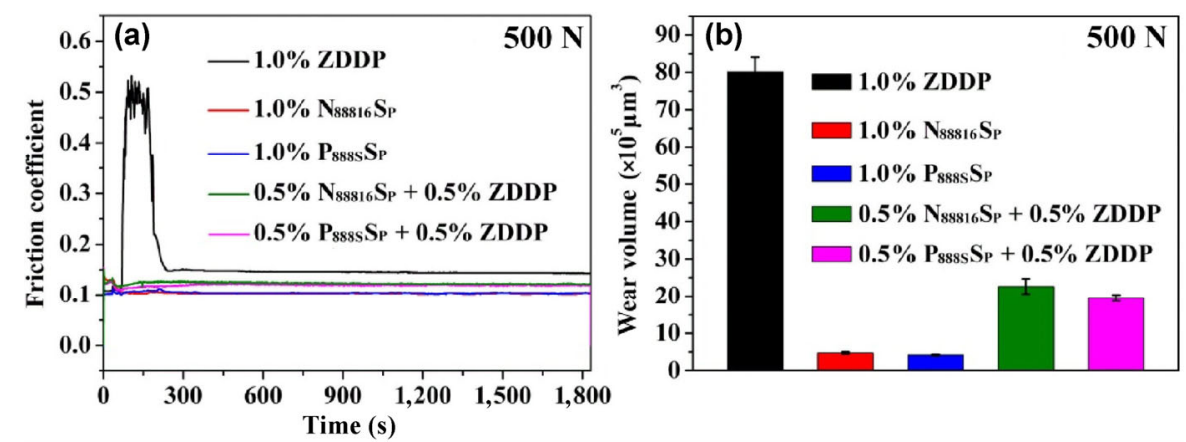

Fig. 10 Friction-reducing and anti-wear properties of ZDDP, $\mathrm{N}_{88816} \mathrm{~S}_{\mathrm{P}}$, and $\mathrm{P}_{888 \mathrm{~S}} \mathrm{~S}_{\mathrm{P}}$ at mass concentrations, namely, $1.0 \mathrm{wt} \%$ ZDDP, $1.0 \mathrm{wt} \% \mathrm{~N}_{88816} \mathrm{~S}_{\mathrm{P}}, 1.0 \mathrm{wt} \% \mathrm{P}_{888 \mathrm{~S}} \mathrm{~S}_{\mathrm{P}}, 0.5 \mathrm{wt} \% \mathrm{~N}_{88816} \mathrm{~S}_{\mathrm{P}}+0.5 \mathrm{wt} \% \mathrm{ZDDP}$, and $0.5 \mathrm{wt} \% \mathrm{P}_{888 \mathrm{~S}} \mathrm{~S}_{\mathrm{P}}+0.5 \mathrm{wt} \%$ ZDDP for steel/steel contacts at $500 \mathrm{~N}, 25 \mathrm{~Hz}$, and RT. 
wear scar surfaces $[2,23]$. To research the feasible tribochemical reaction in the process of friction and to investigate the lubricating mechanism of the IL additives, the XPS spectra of neat ILs and the corresponding worn surfaces are obtained. The XPS spectra of C1s, Fe2p, S2p, P2p, Zn2p, and N1s of worn steel surfaces lubricated by neat PAO10, and the mixtures (the content of the additive: $1 \mathrm{wt} \%$ ) are obtained as depicted in Fig. 11. The binding energies of C1s of ZDDP, $\mathrm{N}_{88816} \mathrm{~S}_{\mathrm{P}}$, and $\mathrm{P}_{8885} \mathrm{~S}_{\mathrm{P}}$ appear at $284.8 \mathrm{eV}$ corresponding to C-C, as illustrated in Fig. 11(a). For the wear scars lubricated by ZDDP, $\mathrm{P}_{8885} \mathrm{~S}_{\mathrm{P}}$, and $\mathrm{N}_{88816} \mathrm{~S}_{\mathrm{P}}$, the peaks of $\mathrm{C} 1 \mathrm{~s}$ are also approximately $284.8 \mathrm{eV}$, indicating the absence of cleavage of the $\mathrm{C}-\mathrm{C}$ bond in the process of friction. The peaks of $\mathrm{Fe} 2 \mathrm{p}$ of wear scars lubricated by neat lubricants appear at $711.3 \mathrm{eV}$ and $725.1 \mathrm{eV}$, as illustrated in Fig. 11(b), which is likely to correspond to $\mathrm{Fe}_{2} \mathrm{O}_{3}, \mathrm{Fe}(\mathrm{OH}) \mathrm{O}$, and $\mathrm{FeOOH}$ [40].

The binding energies of S2p of ZDDP and $\mathrm{N}_{88816} \mathrm{~S}_{\mathrm{P}}$, $\mathrm{P}_{8885} \mathrm{~S}_{\mathrm{P}}$ appear at $162.3 \mathrm{eV}$ and $163.2 \mathrm{eV}$, respectively, which are assigned to the sulfur organic compounds. Furthermore, the peaks of wear scars lubricated by the three lubricants are approximately $168.8 \mathrm{eV}$, which can be ascribed to sulfate compounds [27]. The peak of P2p of ZDDP shifts from $133.5 \mathrm{eV}$ to $133.3 \mathrm{eV}$ after the friction test, and it is assigned to phosphate
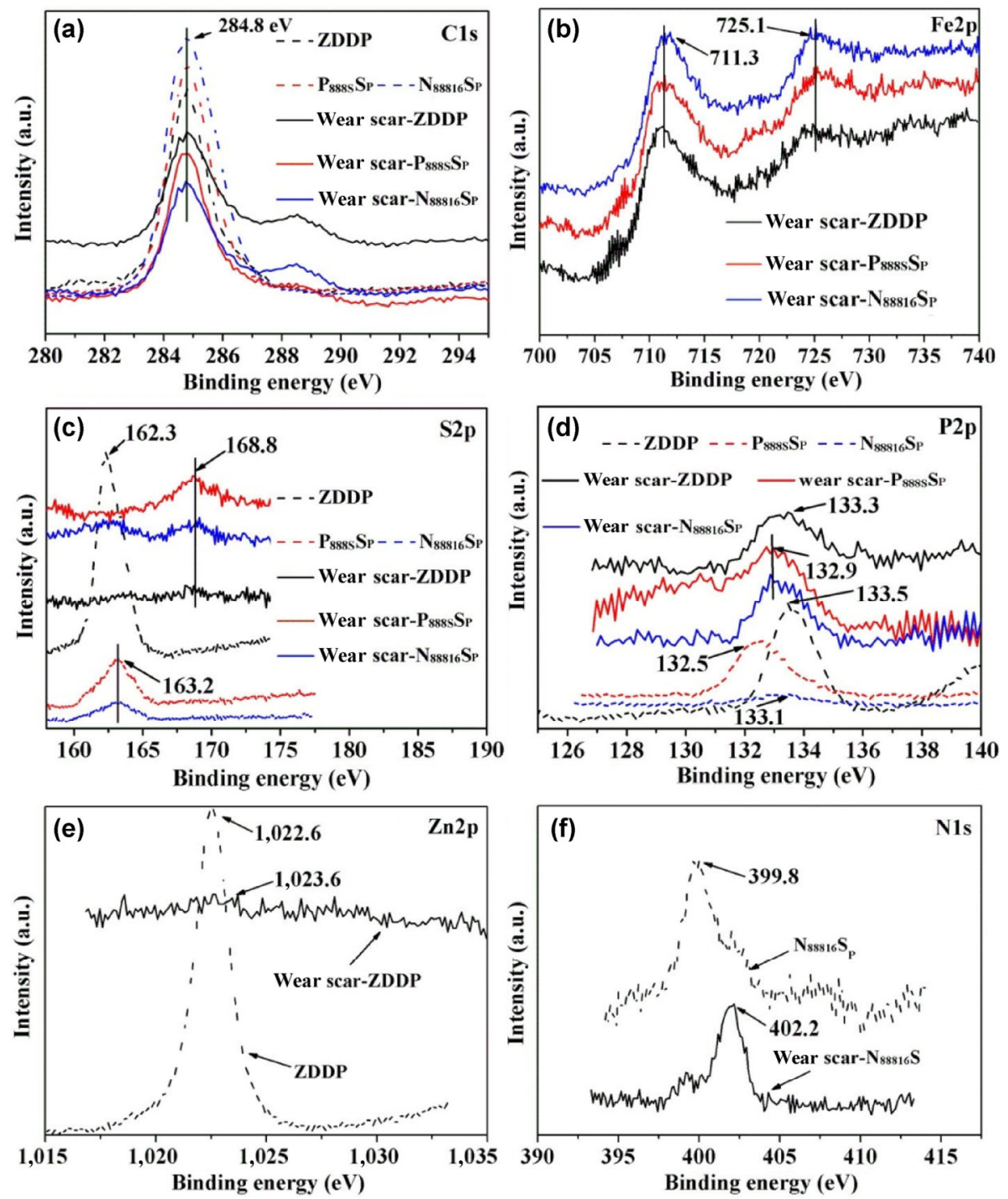

Fig. 11 XPS spectra of (a) C1s, (b) Fe2p, (c) S2p, (d) P2p, (e) Zn2p, and (f) N1s of neat lubricants and corresponding wear scars lubricated by $1 \mathrm{wt} \%$ ZDDP, $1 \mathrm{wt} \% \mathrm{P}_{888 \mathrm{~S}} \mathrm{~S}_{\mathrm{P}}$, and $1 \mathrm{wt} \% \mathrm{~N}_{88816} \mathrm{~S}_{\mathrm{P}}$ respectively, at $300 \mathrm{~N}, 25 \mathrm{~Hz}$, and RT. 
compounds and organic phosphates, respectively [10]. Moreover, the binding energies of $\mathrm{P} 2 \mathrm{p}$ of $\mathrm{P}_{8885} \mathrm{~S}_{\mathrm{P}}$ and $\mathrm{N}_{88816} \mathrm{~S}_{\mathrm{P}}$ vary from $132.5 \mathrm{eV}$ and $133.1 \mathrm{eV}$ to $132.9 \mathrm{eV}$ separately, which are ascribed to organic phosphates and phosphate compounds. Meanwhile, the peaks of Zn2p of ZDDP and the corresponding wear scar are also detected, and it is determined that the binding energies are approximately $1022.6 \mathrm{eV}$ and $1023.6 \mathrm{eV}$, as depicted in Fig. 8(e). The binding energy of N1s of $\mathrm{N}_{88816} \mathrm{~S}_{\mathrm{P}}$ shifts from $399.8 \mathrm{eV}$ to $402.2 \mathrm{eV}$, as illustrated in Fig. 11(f), which corresponds to organic nitrogen compounds and nitrides [7]. The above results indicate that the active elements (such as $\mathrm{S}, \mathrm{P}, \mathrm{Zn}$, and $\mathrm{N}$ ) are likely to react with the surfaces of sliding pairs to form inorganic compounds of higher toughness. Numerous studies have established that the lubricating mechanism of ZDDP can be attributed to the formation of tribochemical film by S, P, and Zn $[4,36,41]$. Therefore, it is deduced that the effective lubricating performance of $\mathrm{P}_{8885} \mathrm{~S}_{\mathrm{P}}$ and $\mathrm{N}_{88816}$ can be attributed to the tribochemical reactions in the process of friction.

\subsubsection{EDS analysis of wear scar surfaces}

EDS as a powerful tool has been widely adopted to investigate the accurate section-distribution of elements of wear scar surfaces $[29,32,42]$. To further study the lubricating mechanism, the section-distribution of $\mathrm{P}, \mathrm{S}, \mathrm{Zn}$, and $\mathrm{N}$ of wear scars lubricated by ZDDP, $\mathrm{P}_{8885} \mathrm{~S}_{\mathrm{P}}$, and $\mathrm{N}_{88816} \mathrm{~S}_{\mathrm{P}}$ at $300 \mathrm{~N}$ and $25 \mathrm{~Hz}$, as illustrated in Fig. 12 and Table 3. It is evident that the mass contents of $\mathrm{P}, \mathrm{S}$, and $\mathrm{Zn}$ of wear scars lubricated by ZDDP are approximately $0.66 \%, 0.43 \%$, and $0.17 \%$, respectively, indicating the reaction of these active elements with the steel surface. The formation of tribochemical film in the sliding process plays the key role in reducing friction and enhancing anti-wear properties, which has been extensively researched $[31,32,36]$. The mass contents of $\mathrm{P}$ and $\mathrm{S}$ increase to $1.20 \%, 0.84 \%$ and $1.26 \%, 1.04 \%$, respectively, when employing $\mathrm{P}_{8885} \mathrm{~S}_{\mathrm{P}}$ and $\mathrm{N}_{88816} \mathrm{~S}_{\mathrm{P}}$ as the lubricant additives. Meanwhile, the results of elemental mapping images intuitively reflect the increase in the masses of $\mathrm{P}$ and S. Moreover, the presence of a certain amount of
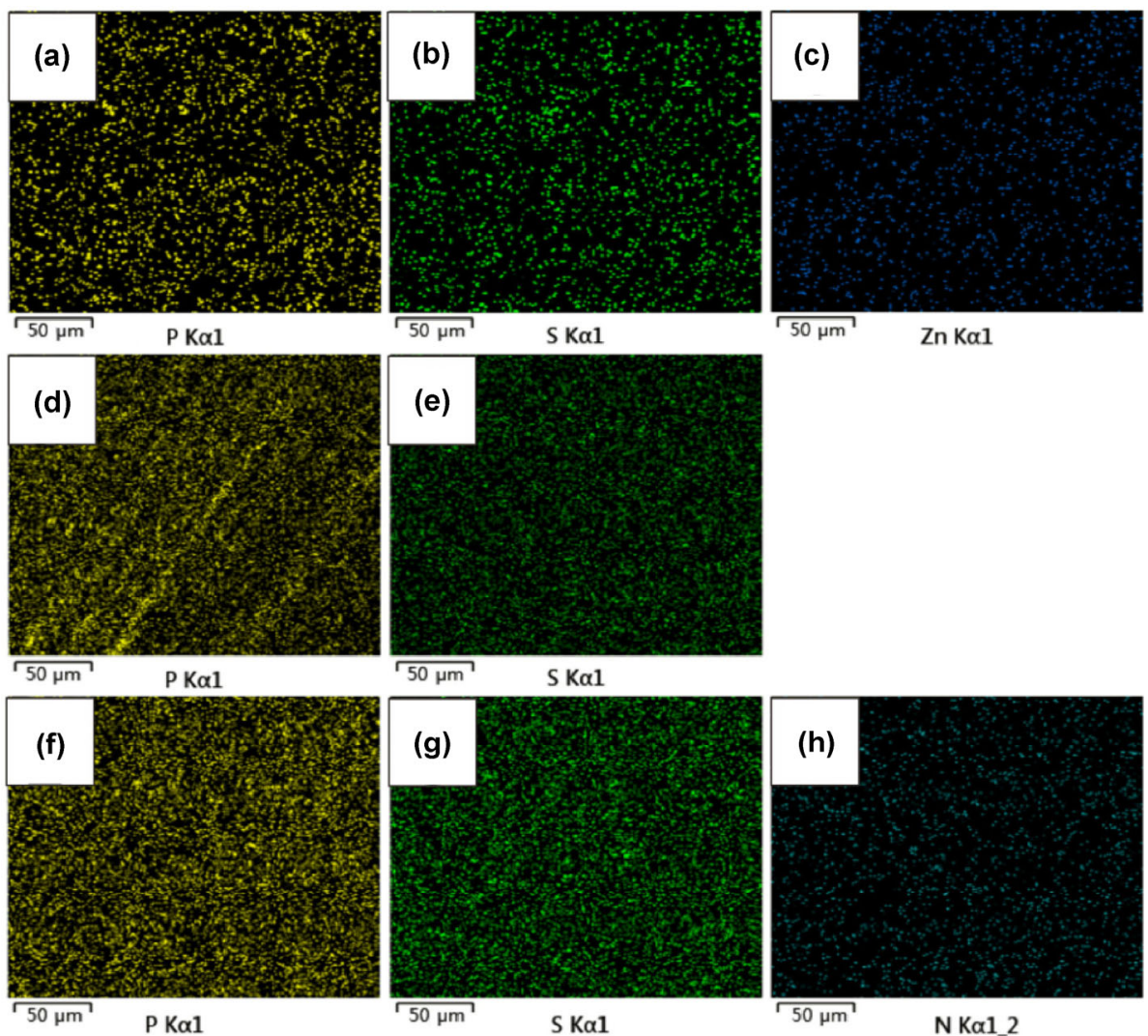

Fig. 12 Section-distribution of wear scars lubricated by (a-c) 1 wt $\%$ ZDDP, (d, e) 1 wt $\% \mathrm{P}_{8885} \mathrm{~S}_{\mathrm{P}}$, and (f-h) $1 \mathrm{wt} \% \mathrm{~N}_{88816} \mathrm{~S}_{\mathrm{P}}$ at $300 \mathrm{~N}$, $25 \mathrm{~Hz}$, and RT. 
Table 3 Element mass content of wear scars lubricated by $1 \mathrm{wt} \% \mathrm{ZDDP}, 1 \mathrm{wt} \%, \mathrm{P}_{888 \mathrm{~S}} \mathrm{~S}_{\mathrm{P}}$, and $1 \mathrm{wt} \% \mathrm{~N}_{88816} \mathrm{~S}_{\mathrm{P}}$ at $300 \mathrm{~N}, 25 \mathrm{~Hz}$, and RT.

\begin{tabular}{ccccccc}
\hline Element & $\mathrm{C}$ & $\mathrm{O}$ & $\mathrm{P}$ & $\mathrm{S}$ & $\mathrm{Fe}$ & \\
\hline $\mathrm{ZDDP}$ & 4.91 & 3.69 & 0.66 & 0.43 & 90.14 & $\mathrm{Zn} / 0.17$ \\
$\mathrm{P}_{888 \mathrm{~S}} \mathrm{~S}_{\mathrm{P}}$ & 4.84 & 3.79 & 1.20 & 1.26 & 88.91 & \\
$\mathrm{~N}_{88816} \mathrm{~S}_{\mathrm{P}}$ & 4.75 & 3.86 & 0.84 & 1.04 & 89.28 & $\mathrm{~N} / 0.23$ \\
\hline
\end{tabular}

nitrogen on the wear scar surface when using $\mathrm{N}_{88816} \mathrm{~S}_{\mathrm{P}}$ as the lubricant additive indicates that the nitrogen in $\mathrm{N}_{88816} \mathrm{~S}_{\mathrm{P}}$ also participates in the tribochemical reaction during the process of friction. According to the above results, it could be concluded that the tribochemical reaction between the active elements of $\mathrm{P}_{8885} S_{\mathrm{P}}$ and $\mathrm{N}_{88816} \mathrm{~S}_{\mathrm{P}}$ and the steel surface results in the effective lubricating property of ILs. Furthermore, the higher amount of phosphate and sulfate compounds generated in the process of friction significantly enhances the lubricating property, particularly the EP performance, of $\mathrm{P}_{8885} \mathrm{~S}_{\mathrm{P}}$ and $\mathrm{N}_{88816} \mathrm{~S}_{\mathrm{P}}$.

\section{Conclusion}

Two types of oil-soluble ILs containing phosphorus and sulfur are synthesized, and as lubricant additives, they exhibit higher lubricating performance than neat PAO10. The comparison with the traditional lubricant additive ZDDP reveals the mixtures containing ILs to exhibit higher EP property and corrosion resistance performance at similar mass concentration. Meanwhile, the ILs as the lubricant additives exhibited higher friction-reducing and AW performance than those of ZDDP as revealed by the frequency and temperature ramp tests; this indicates that the two types of ILs are suitable for use in harsher operational environment. To study the lubricating mechanism of the two ILs as lubricant additives, XPS and EDS were adopted to analyze the chemical compositions and mass contents of the elements of the wear scar surfaces. It was determined that the tribochemical reaction and the higher amount of phosphate and sulfate compounds generated in the process of friction, which significantly enhance the lubricating behavior and EP performance of $\mathrm{N}_{88816} \mathrm{~S}_{\mathrm{P}}$ and $\mathrm{P}_{8885} \mathrm{~S}_{\mathrm{P}}$.

\section{Acknowledgements}

The authors acknowledge the financial support from the National Natural Science Foundation of China (NSFC, Nos.51675512, 51227804, and 51305428), Natural Science Foundation of Gansu Province (No. 1606RJZA051), and the National Key Basic Research and Development (973) Program of China (No. 2013CB632301).

Open Access: The articles published in this journal are distributed under the terms of the Creative Commons Attribution 4.0 International License (http:// creativecommons.org/licenses/by/4.0/), which permits unrestricted use, distribution, and reproduction in any medium, provided you give appropriate credit to the original author(s) and the source, provide a link to the Creative Commons license, and indicate if changes were made.

\section{References}

[1] Holmberg K, Andersson P, Erdemir A. Global energy consumption due to friction in passenger cars. Tribol Int 47: 221-234 (2012)

[2] Yu Q, Huang G, Cai M, Zhou F, Liu W. In situ zwitterionic supramolecular gel lubricants for significantly improved tribological properties. Tribol Int 95: 55-65 (2016)

[3] Sgroi M F, Asti M, Gili F, Deorsola F A, Bensaid S, Fino D, Kraft G, Garcia I, Dassenoy F. Engine bench and road testing of an engine oil containing $\mathrm{MoS}_{2}$ particles as nanoadditive for friction reduction. Tribol Int 105: 317-325 (2017)

[4] Nicholls M A, Do T, Norton P R, Kasrai M, Bancroft G M. Review of the lubrication of metallic surfaces by zinc dialkyl-dithiophosphates. Tribol Int 38: 15-39 (2005)

[5] Singh Y. Tribological behavior as lubricant additive and physiochemical characterization of Jatropha oil blends. Friction 3(4): 320-332 (2015)

[6] Cai M, Liang Y, Zhou F, Liu W. A novel imidazolium salt with antioxidation and anticorrosion dual functionalities as the additive in poly(ethylene glycol) for steel/steel contacts. Wear 306(1-2): 197-208 (2013)

[7] Huang G, Yu Q, Ma Z, Cai M, Liu W. Probing the lubricating mechanism of oil-soluble ionic liquids additives. Tribol Int 107: 152-162 (2017) 
[8] Song Z, Liang Y, Fan M, Zhou F, Liu W. Lithium-based ionic liquids as novel lubricant additives for multiply alkylated cyclopentanes (MACs). Friction 1(3): 222-231 (2013)

[9] Liu W, Y C, Gong Q, Wang H, Wang P. Tribological Performance of Room-Temperature Ionic Liquids as Lubricant. Tribol Lett 13(2): 81-85 (2001)

[10] Cai M, Liang Y, Yao M, Xia Y, Zhou F, Liu W. Imidazolium ionic liquids as antiwear and antioxidant additive in poly(ethylene glycol) for steel/steel contacts. ACS Appl Mater Inter 2(3): 870-876 (2010)

[11] Qu J, Truhan J J, Dai S, Luo H, Blau P J. Ionic liquids with ammonium cations as lubricants or additives. Tribol Lett 22(3): 207-214 (2006)

[12] Fan M, Liang Y, Zhou F, Liu W. Dramatically improved friction reduction and wear resistance by in situ formed ionic liquids. RSC Adv 2(17): 6824-6830 (2012)

[13] Fan X, Xia Y, Wang L. Tribological properties of conductive lubricating greases. Friction 2(4): 343-353 (2014)

[14] Zhou F, Liang Y, Liu W. Ionic liquid lubricants: designed chemistry for engineering applications. Chem Soc Rev 38(9): 2590-2599 (2009)

[15] Liu W, Ye C, Gong Q, Wang H, Wang P. Tribological Performance of Room-Temperature Ionic Liquids as Lubricant. Tribol Lett 13(2): 81-85 (2002)

[16] Pisarova L, Totolin V, Gabler C, Dörr N, Pittenauer E, Allmaier G, Minami I. Insight into degradation of ammoniumbased ionic liquids and comparison of tribological performance between selected intact and altered ionic liquid. Tribol Int 65: 13-27 (2013)

[17] Kronberger M, Pagano F, Pejaković V, Igartua A, Urbistondo E, Kalin M. Miscibility and tribological investigations of ionic liquids in biodegradable esters. Lubr Sci 26(7-8): 463-487 (2014)

[18] Westerholt A, Weschta M, Bösmann A, Tremmel S, Korth Y, Wolf M, Schlücker E, Wehrum N, Lennert A, Uerdingen M, Holweger W, Wartzack S, Wasserscheid P. Halide-free synthesis and tribological performance of oil-miscible ammonium and phosphonium-based ionic liquids. ACS Sustain Chem Eng 3(5): 797-808 (2015)

[19] Qu J, Bansal D G, Yu B, Howe J Y, Luo H, Dai S, Li H, Blau P J, Bunting B G, Mordukhovich G, Smolenski D J. Antiwear performance and mechanism of an oil-miscible ionic liquid as a lubricant additive. ACS Appl Mater Inter 4(2): 997-1002 (2012)

[20] Yu B, Bansal D G, Qu J, Sun X, Luo H, Dai S, Blau P J, Bunting B G, Mordukhovich G, Smolenski D J. Oil-miscible and non-corrosive phosphonium-based ionic liquids as candidate lubricant additives. Wear 289: 58-64 (2012)
[21] Wang H, Lu Q, Ye C, Liu W, Cui Z. Friction and wear behaviors of ionic liquid of alkylimidazolium hexafluorophosphates as lubricants for steel/steel contact. Wear 256(1-2): 44-48 (2004)

[22] Han Y, Qiao D, Zhang L, Feng D. Study of tribological performance and mechanism of phosphonate ionic liquids for steel/aluminum contact. Tribol Int 84: 71-80 (2015)

[23] Wang Z, Xia Y, Liu Z. The rheological and tribological properties of calcium sulfonate complex greases. Friction 3(1): 28-35 (2014)

[24] Li J, Zhang C, Deng M, Luo J. Investigations of the superlubricity of sapphire against ruby under phosphoric acid lubrication. Friction 2(2): 164-172 (2014)

[25] Bonhôte P, Dias A-P, Papageorgiou N, Kalyanasundaram K, Grä1tzel M. Hydrophobic, Highly Conductive AmbientTemperature Molten Salts. Inorg Chem 35(5): 1168-1178 (1996)

[26] Fröba A P, Kremer H, Leipertz A. Density, refractive index, interfacial tension, and viscosity of ionic liquids [EMIM][EtSO4], [EMIM][NTf2], [EMIM][N(CN)2], and [OMA][NTf2] in dependence on temperature at atmospheric pressure. J Phys Chem B 112(39): 12420-12430 (2008)

[27] Huang G, Yu Q, Cai M, Zhou F, Liu W. Highlighting the effect of interfacial interaction on tribological properties of supramolecular gel lubricants. Adv Mater Interfaces 3(3): 1500489 (2016)

[28] Ilanko A K, Vijayaraghavan S. Wear behavior of asbestosfree eco-friendly composites for automobile brake materials. Friction 4(2): 144-152 (2016)

[29] Cartigueyen S, Mahadevan K. Wear characteristics of copperbased surface-level microcomposites and nanocomposites prepared by friction stir processing. Friction 4(1): 39-49 (2016)

[30] Yu Q, Fan M, Li D, Song Z, Cai M, Zhou F, Liu W. Thermoreversible Gel Lubricants through Universal Supramolecular Assembly of a Nonionic Surfactant in a Variety of Base Lubricating Liquids. ACS Appl Mater Inter 6(18): 15783-91574 (2014)

[31] Lin Y C, So H. Limitations on use of ZDDP as an antiwear additive in boundary lubrication. Tribol Int 37: 25-33 (2004)

[32] Ito K, Martin J-M, Minfray C, Kato K. Low-friction tribofilm formed by the reaction of ZDDP on iron oxide. Tribol Int 39: 1538-1544 (2006)

[33] Li J, Xu X, Wang Y, Ren T. Tribological studies on a novel borate ester containing benzothiazol-2-yl and disulfide groups as multifunctional additive. Tribol Int 43: 1048-1053 (2010)

[34] Xiong S, Sun J, Xu Y, Yan X. QSPR Models for the Prediction of Friction Coefficient and maximum non-seizure 
load of lubricants. Tribol Lett 60(1) (2015)

[35] Minfray C, Mogne T L, Lubrecht A A, Martin J M. Experimental simulation of chemical reactions between ZDDP tribofilms and steel surfaces during friction processes. Tribol Lett 21(1): 65-76 (2006)

[36] Spikes H. The history and mechanisms of ZDDP. Tribol Lett 17(3): 469-489 (2004)

[37] Zhou X, Yang H, Wang F. [BMIM]BF 4 ionic liquids as effective inhibitor for carbon steel in alkaline chloride solution. Electrochim Acta 56(11): 4268-4275 (2011)

[38] Qu J, Luo H, Chi M, Ma C, Blau P J, Dai S, Viola M B. Comparison of an oil-miscible ionic liquid and ZDDP as a lubricant anti-wear additive. Tribol Int 71: 88-97 (2014)

[39] Qu J, Barnhill W C, Luo H, Meyer III H M, Leonard D N, Landauer A K, Kheireddin B, Gao H, Papke B L, Dai S.

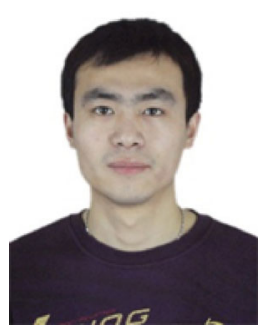

Guowei HUANG. He received his master degree in material science and engineering in 2013 from Shandong Jianzhu University. After then, he was a PhD student in the

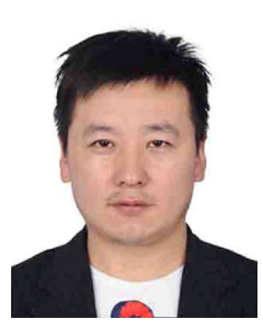

Qiangliang YU. He got his $\mathrm{PhD}$ degree in 2016 at the Lanzhou Institute of Chemical Physics. He is an assistant at the State Key Lab of
Synergistic effects between phosphonium-alkylphosphate ionic liquids and zinc dialkyldithiophosphate (ZDDP) as lubricant additives. Adv Mater 27(32): 4767-4774 (2015)

[40] Cai M, Liang Y, Zhou F, Liu W. Anticorrosion imidazolium ionic liquids as the additive in poly(ethylene glycol) for steel/Cu-Sn alloy contacts. Faraday Discuss 156: 147-157 (2012)

[41] Yin Z, Kasrai M, Fuller M, Bancroft G M, Fyfe K, Tan K H. Application of soft $\mathrm{x}$-ray absorption spectroscopy in chemical characterization of antiwear films generated by ZDDP Part I: The effects of physical parameters. Wear 202(2): 172-191 (1997)

[42] Jiménez A-E, Bermúdez M-D. Ionic liquids as lubricants for steel-aluminum contacts at low and elevated temperatures. Tribol Lett 26(1): 53-60 (2006)

State Key Laboratory of solid lubrication, Lanzhou Institute of Chemical Physics, Chinese Academy of Sciences. His research interests include the design and preparation of novel ionic liquids as lubricant and lubricating additives.

Solid Lubrication in Lanzhou Institute of Chemical Physics, CAS. His research interests are ionic liquids lubricants and anticorrosive additives.

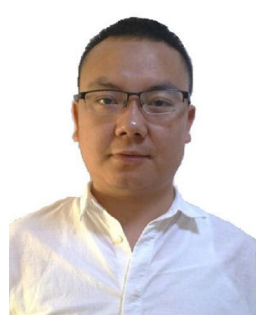

Zhengfeng MA. He received his B.S. degree in chemistry and M.S. degree in polymer chemistry and physics from Lanzhou University in 2011 and 2014 respectively. He joined the State Key Lab of Solid Lubrication in Lanzhou Institute of Chemical Physics, CAS, from 2014. His research areas is polymer lubrication materials. 


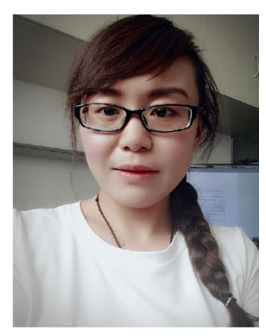

Meirong CAI. She got her $\mathrm{PhD}$ degree in 2012 at the Lanzhou Institute of Chemical Physics. She is an associate professor at the State Key Lab of Solid Lubrication in

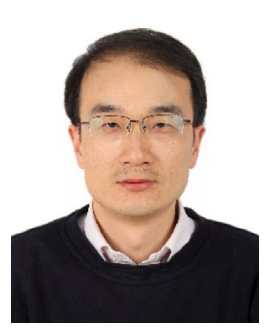

Feng Zhou. He is a full professor in Lanzhou Institute of Chemical Physics, CAS and Deputy director of State Key Laboratory of Solid Lubrication. He gained PhD in 2004 and spent three years (2005-2008) in the Department of Chemistry, University of Cambridge as a research associate. He has published more than 260 journal papers that

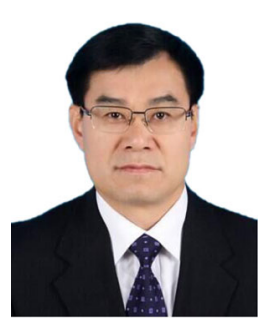

Weimin LIU. He received his Ph.D. degree in lubricating materials and tribology from Lanzhou Institute of Chemical Physics (LICP) of the Chinese Academy of Sciences in 1990. After that, he joined the State Key Laboratory of Solid Lubrication (LSL) of the LICP. From June 1993 to June 1994, he worked as a Visiting Scholar at Pennsylvania State University, USA. In 2013, he was elected the Member
Lanzhou Institute of Chemical Physics, CAS. She has authored or co-authored more than 30 journal papers. Her research interests are ionic liquids lubricants and supramolecular gel lubricants.

received more than 10000 citations and has the H-index 56. His research interests include the bioninspired tribology, biomimic surfaces/interfaces of soft matters, drag-reduction and antibiofouling, functional coatings. He has gained a number of awards including "Outstanding Youth Award" of International Society of Bionic Engineering, 2013. He serves as editorial board member of Tribology International, Journal Fiber Bioengineering and Informatics etc.

of the Chinese Academy of Sciences. Currently, he is a professor of LICP and head of the State Key Laboratory of Solid Lubrication. Up to now, he has published more than 500 papers with citation over 20000. He holds 80 Chinese patents and 1 US patent; won 2 National Awards for Technological Invention (second class) and 1 National Award for Natural Sciences (second class). Currently, his research interests mainly focus on space and aviation lubrication, high performance lubricating materials and Tribochemistry. 